\title{
The perspective of optical measurement methods in forestry
}

Sascha Lummitsch, Erik Findeisen, Moritz Haas, Christin Carl

Sascha Lummitsch, Erik Findeisen, Moritz Haas, Christin Carl, "The perspective of optical measurement methods in forestry," Proc. SPIE 11144, Photonics and Education in Measurement Science 2019, 111441E (17 September 2019); doi: 10.1117/12.2533490

SPIE Event: Joint TC1 - TC2 International Symposium on Photonics and Education in Measurement Science 2019, 2019, Jena, Germany 


\title{
The perspective of optical measurement methods in forestry
}

\author{
Sascha Lummitsch ${ }^{1}$, Erik Findeisen ${ }^{1}$, Moritz Haas ${ }^{1}$, Christin Carl $^{1}$ \\ ${ }^{1}$ Forestry and Ecosystem Management, Faculty of Landscape Architecture, Horticulture and Forestry, University of \\ Applied Sciences Erfurt, Leipziger Straße 77, 99085 Erfurt, Germany; Sascha.Lummitsch@fh-erfurt.de; \\ erik.findeisen@fh-erfurt.de; moritz.haas@fh-erfurt.de; christin.carl@fh-erfurt.de
}

\begin{abstract}
Forestry in Germany and all over the world is undergoing a big change based on the digitalization. A combination of recent advances in measurement technology offers strong possibilities to use optical measurement systems as an addition to the conventional forestry machinery. Cameras, lasers, and sensors extend the accuracy of how we collect bio data, e.g. diameters, distances, heights, the total amount of wood volume, timber etc. Detailed data of the plant structure as well as calamities are the basis to get a better overview and improve the downstream process chain. Forestry is an economical field working with natural products, especially wood. Therefore, foresters need to determine the exact amount of the regrowing products. The certification systems like PEFC (Program for the Endorsement of Forest Certification Schemes) and FSC (Forest Stewardship Council) rely on precise data of wood volume, which has been harvested. Hence, nature product producer need more techniques and optical measurement systems, which are adapted to this very rough field of application. The cameras will be exposed to rain, fog, heat, cold, ice, mud, earth, dirt, stones, vibrations, and more effects in the outdoor use. This paper examines some of the recent projects and joint-ventures between forestry and photo-optical measurements and describes how they can be used to bridge the gap between two disciplines, addressing areas of both sides. We need to exchange our knowledge to find new ways of applying optical systems in Forestry.
\end{abstract}

Keyword List: optical measurement, forestry, laser, cameras, forestry machinery

\section{INTRODUCTION}

Aiming at updating the general knowledge and identifying the future direction of technological improvements in forestry, this article reviews the recent advances, perspectives and challenges of photo-optical measurements. Section 1 introduces the development and the background. Section 2 describes the use of drones in forestry. New technical developments, e.g. the laser scanning, open new perspectives on improving data collection in the field of forestry and might provide answers to some previous challenges including long distance live data measurement, airborne laser scanning above and below the leaf roofs, more precise height measurements and slope effect correction, faster and more accurate diameter measurement, meticulously definition of logged tree volumes with or without the bark. Section 3 presents optical measurement in addition to established forest machineries such as harvesters, tractors, reapers, and introduces new progress and opportunities provided by laser scanners. While much progress has been achieved, in modern harvesting machinery, many challenges remain:

(1) The advantages of camera and laser-based measurement must be applied in the working fields of the forestry starting from the first step of the process chain to address new problems accompanying the requirements of increasing accuracy and new applications.

(2) Small dimensioned wood and stems are not measured in the field due to a lack of convenient operational methods.

Photonics and Education in Measurement Science 2019, edited by Maik Rosenberger,

Paul-Gerald Dittrich, Bernhard Zagar, Proc. of SPIE Vol. 11144, 111441E

(C) 2019 SPIE · CCC code: $0277-786 X / 19 / \$ 21 \cdot$ doi: $10.1117 / 12.2533490$ 
(3) The application of laser scanning is an opportunity for providing answers to the challenges of three-dimensional information.

(4) The forest industry needs to step out of the old-fashioned measurement methods and open to the technological und scientific approach of the $21^{\text {st }}$ century. Cloud computing, artificial intelligence, big data, laser scanning, and 3D live data measurement will change the way of working.

One of the key components in modern forest operation is inventory [1]. The tree species can be estimated using cameras and computer vision techniques [2]. Tremblay et al. [3] point out that the extraction of diameters from LiDAR point clouds via 3D mapping can be "[...] one of the key elements to the development of future intelligent forestry machinery." We think, these innovations will be making their way into forestry, but not instantly. Therefore, we present the following chapters, which need technical improvements.

\section{DRONES IN FORESTRY}

Drones or UAV (unmanned aerial vehicle) are platform's, which enables a bird's view [4]. Equipped with different camera systems like RGB (red, green, blue), multispectral, infrared, and thermal cameras as well as laser or radar systems, UAV's enable new perspectives of the surface of the environment, landscape, cities etc. UAV's allow the detection of ecosystem structures and changes offering a higher spatial resolution of small, specific, and detailed vegetation structures [5,6]. Additionally, UAS have quick turnaround times, are very cost-efficient and are useful supplements to data from satellites, airplanes, terrestrial manual, and other data analyses. In forestry drones were used to detect trees [7], as well as to monitor the infestation levels of pests [8], to find bark beetles as early as possible [9], to monitor wildlife animals, develop forest inventories [10], monitor wind damage [11], invasiveness analysis [12,13], to quantify the expected flower [6] and seeds [14] as well as for autonomous reforestation.

In combination with the ongoing described applications of these article drones enable the data collection of forest structures from the air. Thereby, 3D point clouds can be generated via LiDAR systems or by applying a high overlap of camera images $[15,16]$. With the aid of the 3D point cloud data the vegetation height (Digital Surface Model - Digital Terrain Model) and volume can be measured as well as the number of trees can be calculated. Moreover, the crown structure can be analyzed. In images further structures and features of tree species and plants are analyzable. Nevertheless, by improving drone sensors and analyzing tools further forest data can be generated. Thereby, the focus might be on sensors and systems, which generate a lot of helpful data for forest workers, owner, saw miles etc. All in all, drones are an additional platform to generate forest data and useful information.

\section{BIOMASS MEASUREMENT IN FORESTRY}

The process chain of lumbering starts with the marking of trees. The forester uses marking spray to display the trees for future harvesting. During this process of walking through the stock of trees he accesses every single tree and addresses it regarding the species and its silvicultural standing within the population. Now, the decision which tree to harvest is performed manually by a technician. Even though the results depending on the technician differ, the process is very time consuming and expensive [17] we consider this process as necessary. Furthermore, the technician can collect all the data of the outgoing stock, since he is standing right in front of the trees - with innovative measurement tools.

The University of Applied Science Erfurt develops a handheld device based on 3D laser scanning and synchronized diameter measurement to determine additional data such as diameter of the tree, species, wood quality and geo location. In combination of the height of the tree the precise amount of wood volume can be measured. This simple data collection has a huge effect on the ongoing process. The worker doesn't lose time for additional measuring, because the shot and recording are embedded in his working section. Over and above that data will be used for the contractors to specify the amount of wood, the quality and the species of trees which will be logged. The following advantages due to the use of optical measurement will be seen:

a) Data collection of the most important parameters to determine the timber volume, which leads to more accurate planning in selling, marketing, forecasting and contract negotiation for the owner. 
b) A fast collection of the needed data within the operational work. The technician is not replaced by a camera or robotic system, but he uses a camera-based handheld to collect more and precise data. The new handheld is one example how optical measurement and forestry are combined. However, the process of marking the trees is very time-consuming and labor-intensive but it will not be replaced so quickly. Cameras and laser scanners are a tried and tested remedy, which will have a huge impact on the accuracy of data collection and for work safety as well.

The forest conversion is the leading topic in forestry due to the climate change. Storm damage and bark beetle [18] infestations have already caused considerable damage in the last decades. The large-scale natural forest regenerations must be properly maintained in order to ecologically stabilize the value-added usable timber assortments. At the same time, many species of coniferous and deciduous trees show increased susceptibility to biotic and abiotic sources [19], so that in future only suitable mixed forests can be expected to have ecologically stable and economically viable forest structures. The small dimensioned wood (outgoing stock) to be extracted during the development of such mixed stocks must be clearly measurable in order not only to comply with the legal framework of sustainable forest management but also not to overutilize the resource wood to avoid scarcity of resources. For the field of highly mechanized harvesting with harvesters, there is the electromechanical determination of the diameter and the length, from which the volume is calculated electronically. This method does not work for the small dimensioned timber $(<15 \mathrm{~cm}$ in diameter) [20]. An alternative of volume determination in real time when working in the area does not exist for the small dimensioned timber so far. This is the baseline for the development of an optical measuring system for the quantification of the volume of small dimensioned wood harvesting with reapers or collector aggregates of forest machinery. Despite the great "hype" of 3D measurement no industrial measuring systems are yet available for forest technology. Intelligent 3D camera systems that carry out the complete industry-related data processing in the measuring system itself and transmit only a minimum of information are currently not available. The development of a 3D measuring hardware that is precisely adapted to the needs of the harsh environment of optical measurement in forests is needed.

\section{ROAD SCANNING SYSTEMS}

The core element in the forestry harvest chain for the realization of a modern, multifunctional forestry is the accessibility of the forest sections via an appropriate infrastructure. Furthermore, a staggered system over different forest path classes down to the back lanes for the fine development of the respective forestry sections is used. The condition of the forest roads, their trafficability, and usability for different forestry measures is therefore essential for proper management and

maintenance. However, forest roads are subject to continuous stress, e.g. due to their position, weather conditions, and machine use. This can be reflected in erosion, vegetation covering, changes in profile, washouts, and deposits or even in punctual events of damage, making use impossible or only possible to a limited extend. Over the course of time such marginal damage or restriction of the clearance gauge resulting from vegetation development can result in massive adverse effects on its use. For all these tasks there is no forest-based and economically applicable evaluation system on the market. At this point the support of modern laser scanning systems is needed. In the sensor development and selection especially, the environmental conditions are to be considered. In order to distinguish fluctuating temporary pathways (puddles, lumbers on the pathway, and leaves in the draining ditch) from permanent pathways (including cracks in the ground) the corresponding spectral data must be registered in addition to the 3D spatial data. As mentioned by Google - Google Street View Applications - might be a technical base to collect 3D data of the forest roads [21]. New ideas and the implementation of road measurement systems are needed.

\section{OPTICAL MEASUREMENT OF TREES AND TREE STEMS}

Dendrology is the science of woody plants. In that field, a common task is the study of tree-rings (growth-rings). Tree growth is not steady but can mostly be divided into two periods: The early phase in which thin walled cells (earlywood) appear, and the later growing season, where thick-walled narrow cells (latewood) are generated [22]. 
Annual growth-rings can provide a lot of information like the age of the tree, growing-conditions, historic climate data and densities of the wood itself. The last point in special is of great interest for the wood sawing industry, because of the influence densities have on wood quality and therefore on the products, which can be provided.

However, the extraction of these information is based on old techniques, like manual measurement, counting annual rings or semi-automatic analysis. For the sake of completeness, there are parameters of wood quality, which are detected technically e.g. curvature or rotation. The ring width however, and thus the density, is optically inspected by a skilled worker. This happens while the log passes by on a conveyor belt. If ring width should be considered while sorting, this method is state of the art [24].

There were some experimental setups of computer-based analyses of timber end faces [23,27]. These studies show the requirements and challenges, which a functional system must fit. However, technological progress since 2009 in optical measurement and computer-based analyses is immense. There are present projects, such as READiStrength, where "current developments in roundwood characterization technology [...], as well as established methods [...] [are used] with the aim of developing combined strength grading scenarios for round and sawn timber [26]." In the opinion of the authors, optical data could be used for much more than qualitative sorting of logs. To give two examples of future innovations:

a) a method to draw conclusions on how logs are conditioned inside.

b) the creation of a serial number using unique distinguishing marks on the log end face or complete stem.

To a) Drawing conclusions on how logs are conditioned inside

There is much more information, which can be gained by the observation of timber-surfaces. Thinks like branches, parasites (fungi, insect holes, plants), necrosis, etc. can be detected, which mostly have impact on the inner structure of the log. This could be used for further decision-making, e.g. whether a stem is proper for constructional issues or better be used in furniture industry. This would improve resource efficiency. Technically, systems must be able to make and analyze images very fast, due to high process tempo, which is often found in sawmills. In addition, there are more environmental challenges like dirt, dust or changing temperature. The high-resolution pictures could probably be analyzed by using 3D-Simulations of tree-growing. Nevertheless, the distributors of optical measurement methods should be asked, what is realistically possible in this case.

\section{$\underline{\text { To b) Creation of a serial number using unique distinguishing marks }}$}

This could be used to identify the wooden products back to its roots and therefore to its place of growth. Since reduction of transport routes especially in Germany gain in importance, benefits could even lead into a new certification such as "Holz von hier" [logs from locals] [25], but with a higher traceability for the end customer. The technique could be, to convert all individual characteristics (type of wood, growth-rings widths, ovality, curvature, rotation) into a code, which might be printed onto the log by laser. Analogous to QR or bar codes, customers may be able to scan the information with their smartphone or research online.

\section{CONCLUSIONS}

Some basic needs and the far-reaching possibilities of optical measurement methods in forestry are reviewed to update the general knowledge and identify the possible overlaps of these two working fields. Recent advances and new developments are mentioned to provide a basis for the use of modern cameras and laser systems in forestry. The environmental conditions are many times more difficult in the field than in the laboratory, which is why research and manufacturers are being sought that can meet these demands.

3D simulations are one way to train machine learning techniques [3]. The laser scanner provides 3D point cloud information, which is a relatively appealing new data source. The data acquisition mechanism of terrestrial and airborne 
laser scanners is similar, although their resolution and footprint sizes are different. Airborne systems like drones and LIDAR is already used in forestry $[5,6,8,10]$, but research is still in its infancy.

\section{REFERENCES}

[1] Liang, X., Kankare, V., Hyyppa, J. et al. "Terrestrial laser scanning in forest inventories". ISPRS J. Photogramm., 115:63 - 77, (2016).

[2] Carpentier, M., Giguere, P., Gaudreault, J. "Tree species identification from bark images using convolutional neural networks". In IEEE/RSJ Int. Conf. Int. Robot., pages 1075-1081, (2018).

[3] Tremblay, J.-F., Béland, M., Pomerleau, F., Gagnon, R., Giguère, P. “Automatic 3D Mapping for Tree Diameter Measurement in Inventory Operations", ResearchGate (2019).

[4] Krishna, K. R. [Agricultural drones: a peaceful pursuit], Apple Academic Press. (2018).

[5] Tang, L., Shao, G. "Drone remote sensing for forestry research and practices,". J. For. Res. 26, 791-797 (2015).

[6] Carl, C., Landgraf, D., van der Maaten-Theunissen, M., Biber, P., Pretzsch, H. "Robinia pseudoacacia L. Flower Analyzed by Using Unmanned Aerial Vehicle (UAV),” Remote Sens. 9, 1091 (2017).

[7] Horton, R., Cano, E., Bulanon, D., Fallahi, E. “Peach Flower Monitoring Using Aerial Multispectral Imaging,” J. Imaging 3, 2 (2017).

[8] Lehmann, J.R.K., Nieberding, F., Prinz, T., Knoth, C. "Analysis of unmanned aerial system-based CIR images in forestry-A new perspective to monitor pest infestation levels,". Forests 6, 594-612 (2015).

[9] Näsi, R., Honkavaara, E., Lyytikäinen-Saarenmaa, P., Blomqvist, M., Litkey, P., Hakala, T., Viljanen, N., Kantola, T., Tanhuanpää, T., Holopainen, M. "Using UAV-based photogrammetry and hyperspectral imaging for mapping bark beetle damage at tree-level," Remote Sens. 7, 15467-15493 (2015).

[10] Mund, J.-P., Cremer, T., Krause, S. „Potenzial und Perspektive: Drohnen in der Forstwirtschaft,“ AFZ DerWald 17, 43-46, (2017).

[11]Duan, F., Wan, Y., Deng, L. "A Novel Approach for Coarse-to-Fine Windthrown Tree Extraction Based on Unmanned Aerial Vehicle Images," Remote Sens. 9, 306 (2017).

[12] Lehmann, J.R., Prinz, T., Ziller, S.R., Thiele, J., Heringer, G., Meira-Neto, J.A., Buttschardt, T.K. "Open-source processing and analysis of aerial imagery acquired with a low-cost unmanned aerial system to support invasive plant management," Front. Environ. Sci. 5, 44, (2017).

[13] Carl, C., Lehmann, J. R., Landgraf, D., Pretzsch, H. "Robinia pseudoacacia L. in Short Rotation Coppice: Seed and Stump Shoot Reproduction as well as UAS-based Spreading Analysis," Forests, 10(3), 235, (2019).

[14] Eusemann, P., Liesebach, M., Liesebach, H. „Mit Drohnen Ernteaussichten in Saatgutbeständen erkunden,“ AFZ Der Wald 10, 28-30 (2017).

[15] Ota, T., Ogawa, M., Mizoue, N., Fukumoto, K., Yoshida, S. "Forest Structure Estimation from a UAV-Based Photogrammetric Point Cloud in Managed Temperate Coniferous Forests," Forests 8, 343 (2017).

[16] Mlambo, R., Woodhouse, I.H., Gerard, F., Anderson, K. "Structure from Motion (SfM) photogrammetry with drone data: A low cost method for monitoring greenhouse gas emissions from forests in developing countries," Forests 8, 68 (2017).

[17] Vitkova, L., Ni Dhubhain, A., Pommerening, A. "Agreement in Tree Marking: What Is the Uncertainty of Human Tree Selection in Selective Forest Management?" Forest Sci., 62(3):288-296, (2016).

[18] Christiansen, E., Waring, R., Berryman, A. "Resistance of conifers to bark beetle attack: Searching for general relationships", Forest Ecology and Management (1987).

[19] Anderegg, W., Kane, J., Anderegg, L. "Consequences of widespread tree mortality triggered by drought and temperature stress", Natrue climate change 3, 30-36 (2013).

[20] Pröll, W. "Was man über Harvester wissen sollte - Teil I. Land Technik Leute", Pöllau (Sept. 04), 16-18 (2016).

[21] Anguelov, D. et al "Google Street View: Capturing the world at street level”, Computer 43(6), 32-38, (2010).

[22] Böhlmann, Dietrich. Gehölzbiologie "Warum Bäume nicht in den Himmel wachsen". 2., korrigierte Auflage. Wiebelsheim: Quelle \& Meyer Verlag (2013).

[23] Cerda, Mauricio; Hitschfeld-Kahler, Nancy; Mery, Domingo (Hg.). "Robust tree-ring detection", Springer (2007). 
[24]DFWR; VDS "Rahmenvereinbarung für die Werksvermessung von Stammholz". Online link: http://www.werkeingangsvermessung.info/index.php?Level=8\&menu=download (2015).

[25] HOLZ VON HIER gemeinnützige GmbH: "Das Umweltzeichen”, Creußen. Online link: http://www.holz-vonhier.de/ueber-holz-von-hier/das-umweltzeichen (2019).

[26] Holzforschung Austria - Österreichische Gesellschaft für Holzforschung: "READiStrength", Wien. Online link: http://www.holzforschung.at/projektdetails.html?\&tx_ttnews\%5Btt_news\%5D=473\&cHash=af05dba688bc4b3f b21e2564bb1ec45a (2019).

[27] Norell, Kristin (Hg.) “An automatic method for counting annual rings in noisy sawmill images”, Springer (2009). 